\title{
Extraction of Surface Water Bodies in Anantapur District Using QGIS
}

\author{
N. Ashokkumar ${ }^{1 *}$ M.V. Ramana ${ }^{2}$, M. Raghu Babu ${ }^{3}$, \\ P. Prasuna $\operatorname{Rani}^{4}$ and B. Ravindra Reddy ${ }^{5}$ \\ ${ }^{1}$ Department of Soil and Water Conservation Engineering, College of Agricultural \\ Engineering, Madakasira-515301, India \\ ${ }^{2}$ Department of Agricultural Engineering, Agriculture College, Tirupati, India \\ ${ }^{3}$ Department of Irrigation and Drainage Engineering, College of Agricultural Engineering, \\ Madakasira-515301, India \\ ${ }^{4}$ Geospatial Technology Center, Lam, Guntur, India \\ ${ }^{5}$ Department of Statistics, S.V. Agricultural College, Tirupati, India \\ *Corresponding author
}

\section{A B S T R A C T}

\section{Keywords}

Surface water

bodies, Area,

NDWI, KML etc.

Article Info

Accepted:

10 November 2020

Available Online:

10 December 2020
Several surface water bodies exist in Anantapur district, Andhra Pradesh and A robust methodology has been developed for extraction of water spread areas of the district, based on the processing of satellite images with open-source data and software solutions. Anantapur district lies between $13^{\circ} 40^{\prime}$ and $15^{\circ} 15^{\prime}$ northern latitude and $76^{\circ} 50^{\prime}$ and $78^{\circ} 30^{\prime}$ eastern longitude. It is bounded by Bellary, Kurnool district on the north, Cuddapah district of Andhra Pradesh and Kolar district of Karnataka on South East and North respectively. QGIS functions as geographic information system (GIS) software, allowing users to analyze and edit spatial information, in addition to composing and exporting graphical maps. QGIS supports both raster and vector layers; vector data is stored as either point, line or polygon features. Multiple formats of raster images are supported, and the software can georeference images. The classification of extracted surface water bodies from 2006 to 2015 carried out and evaluated. The regression mean square $\left(R^{2}\right)$ value is 0.3885 for the trend analysis of number of water bodies, and the maximum and minimum number of water bodies was observed during 2014 and 2007 respectively. The $\mathrm{R}^{2}$ value is 0.482 for the trend analysis of surface water bodies and maximum and minimum area of water bodies was observed for the years 2014 and 2006 respectively.

\section{Introduction}

Surface water bodies, such as rivers, lakes, and reservoirs, play important roles in socioeconomic development and ecosystem balance and provide irreplaceable natural resources for human survival and development. Under the influences of climate change and human activities, the spatial distribution and inherent biochemical components of surface water bodies are undergoing great changes. Timely monitoring 
on the dynamics of surface water bodies is therefore of great significance for waterrelated studies and planning activities, such as water resource management, water disaster prevention and water environment protection. Remote sensing is a useful technique for monitoring changes of earth's surface and provides significant data sources for surface water extraction.

Monitoring of water bodies such as reservoirs, minor irrigation tanks and water conservation structures etc., plays an important role in regional level analysis. Several surface water bodies exist in Anantapur district, Andhra Pradesh and A robust methodology has been developed for extraction of water spread areas i.e., by using a water index, namely, the Normalized Difference Water Index of the district, based on the processing of satellite images with open-source data and software solutions. The water index is a simple and effective surface water extraction method for identifying surface water bodies by enhancing the water signal and suppressing the signals of other surface materials using band math. McFeeters (1996) designed the normalized difference water index (NDWI) based on the green and near-infrared (NIR) bands of multispectral scanner images. The study focuses on the usage of open-source data and QGIS software (Silviya et al., 2020).

\section{Study area}

Anantapur district lies between $13.40^{\circ}$ to $15.15^{\circ} \mathrm{N}$ latitude and $76.50^{\circ}$ to $78.30^{\circ} \mathrm{E}$ longitude. The geographical area of the district is 19,13,000 hectares (Fig. 1).

\section{Materials and Methods}

\section{Methodology for extraction of water spread areas}

First Anantapuramu shape file is created and KML boundary file is formed, then after the registration in USGS website, data is downloaded from the USGS website by the input of KML boundary file as input search criteria. Atmospheric correction is done for the data downloaded from the Website with the help SCP plugin. False Color Composite is formed and NDWI is calculated after the correction and NDWI formed to be clipped with Anantapuramu district shape file and reclassification of NDWI layer is done. Then it is converted from raster to vector and water spread areas are extracted and calculated as shown in the Fig. 2.

\section{Results and Discussion}

The extracted surface water bodies from 2006 to 2015 carried out and represented with Fig. 3.

From the Table 1, under surface water area below 0.5 ha, the maximum number of surface water bodies is 96103 in the year 2007 and the minimum number of surface water bodies are 949 in the year 2014. The surface water areas between 0.5 ha to 1 ha, the maximum number of surface water bodies are 13246 in the year 2007 and the minimum number of surface water bodies are 104 in the year 2014. The surface water areas between 1 ha to 2 ha, the maximum number of surface water bodies are 8641 in the year 2007 and the minimum number of surface water bodies are 60 in the year 2014. The surface water areas between 2 ha to 10 ha, the maximum number of surface water bodies are 9136 in the year 2007 and the minimum number of surface water bodies are 55 in the year 2014 . The surface water areas between 10 ha to 50 ha, the maximum number of surface water bodies are 3338 in the year 2006 and the minimum number of surface water bodies are 34 in the year 2014. The surface water areas between 50 ha to 100 ha, the maximum number of surface water bodies are 627 in the year 2006 and the minimum number of surface water bodies are 2 in the year 2014 . 
The surface water areas more than 100 ha, the maximum number of surface water bodies are 821 in the year 2012 and the minimum number of surface water bodies are 2 in the year 2010 .

Table.1 Classification of area and number of surface water bodies from 2006 to 2015

\begin{tabular}{|l|c|c|c|c|c|c|c|c|c|c|}
\hline Classification /Year & $\mathbf{2 0 0 6}$ & $\mathbf{2 0 0 7}$ & $\mathbf{2 0 0 8}$ & $\mathbf{2 0 0 9}$ & $\mathbf{2 0 1 0}$ & $\mathbf{2 0 1 1}$ & $\mathbf{2 0 1 2}$ & $\mathbf{2 0 1 3}$ & $\mathbf{2 0 1 4}$ & $\mathbf{2 0 1 5}$ \\
\hline Area (ha) $<=\mathbf{0 . 5}$ & 77527 & 96103 & 4373 & 56638 & 8449 & 62219 & 56589 & 4373 & 949 & 5401 \\
\hline $\mathbf{0 . 5}>$ Area (ha) >= 1.0 & 7115 & 13246 & 508 & 5922 & 227 & 6245 & 8762 & 508 & 104 & 651 \\
\hline $\mathbf{2}>$ Area (ha) >= 1 & 4858 & 8641 & 303 & 3800 & 165 & 4393 & 5721 & 303 & 60 & 326 \\
\hline $\mathbf{1 0}>$ Area (ha) >= 2 & 6886 & 9136 & 349 & 5053 & 205 & 5976 & 6081 & 349 & 55 & 405 \\
\hline $\mathbf{5 0}>$ Area (ha) >= 10 & 3338 & 2943 & 161 & 2396 & 60 & 2466 & 2049 & 161 & 34 & 107 \\
\hline $\mathbf{1 0 0}>$ Area (ha) >= 50 & 627 & 563 & 14 & 567 & 8 & 432 & 461 & 14 & 2 & 8 \\
\hline $\begin{array}{l}\text { Area (ha) >= 100 } \\
\text { Total number of surface } \\
\text { water bodies }\end{array}$ & 632 & 804 & 17 & 686 & 5 & 333 & 821 & 17 & 9 & 8 \\
\hline $\begin{array}{l}\text { Total area of the water } \\
\text { bodies (ha) }\end{array}$ & 508673.4 & 490873.3 & 197047.4 & 415025.6 & 5015.7 & 239111.4 & 483472.3 & 10737.7 & 4246.6 & 8280 \\
\hline
\end{tabular}

Fig.1 Study area of Anantapur district

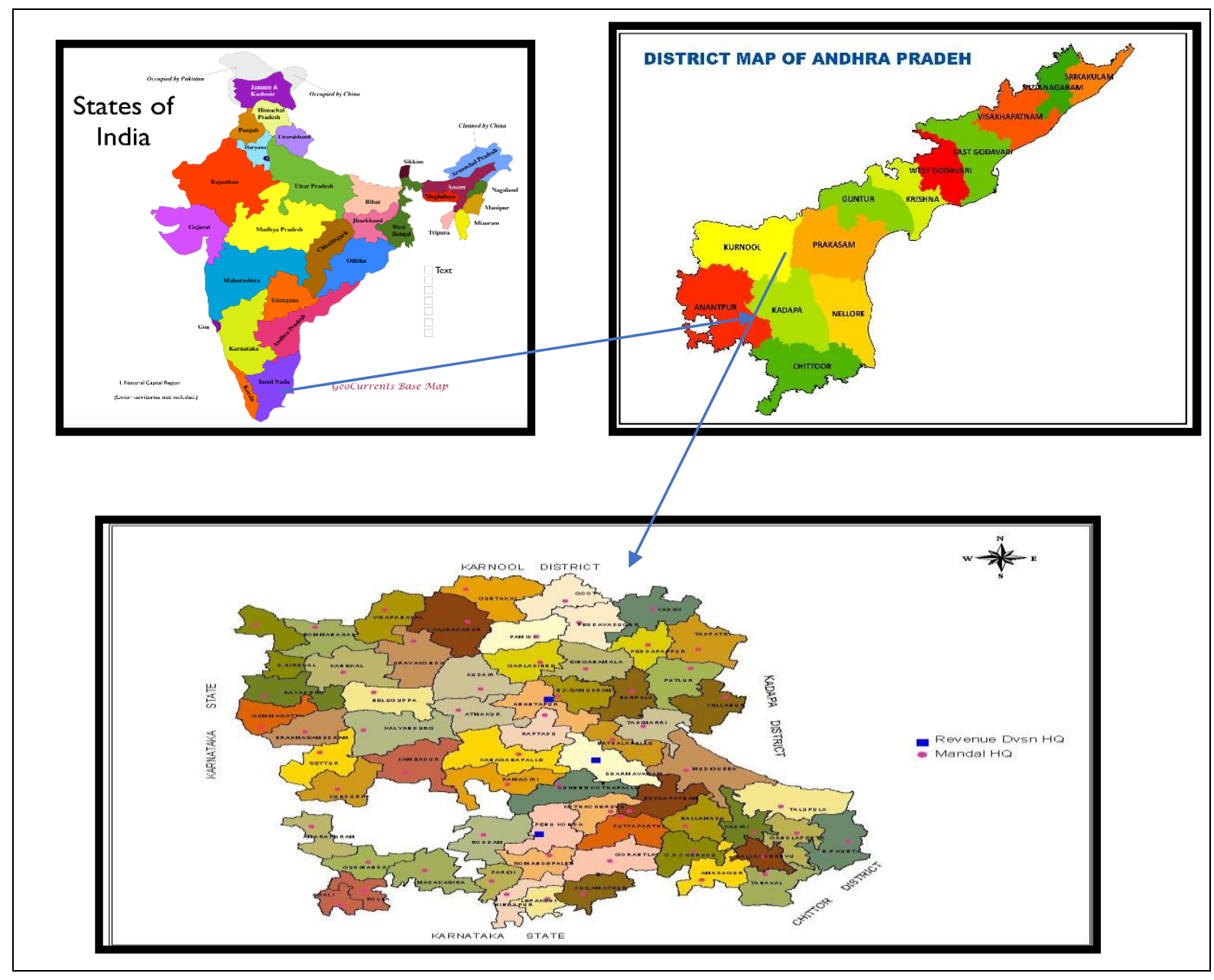


Fig.2 Flow chart of methodology for extraction of water spread areas

Creation of Anantapuramu shape file

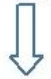

Formation of KML boundary file for Anantapuramu district

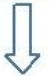

Registration in USGS website<smiles>C1=CC=C1</smiles>

Downloading data from USGS website by input of KML boundary file as search criteria

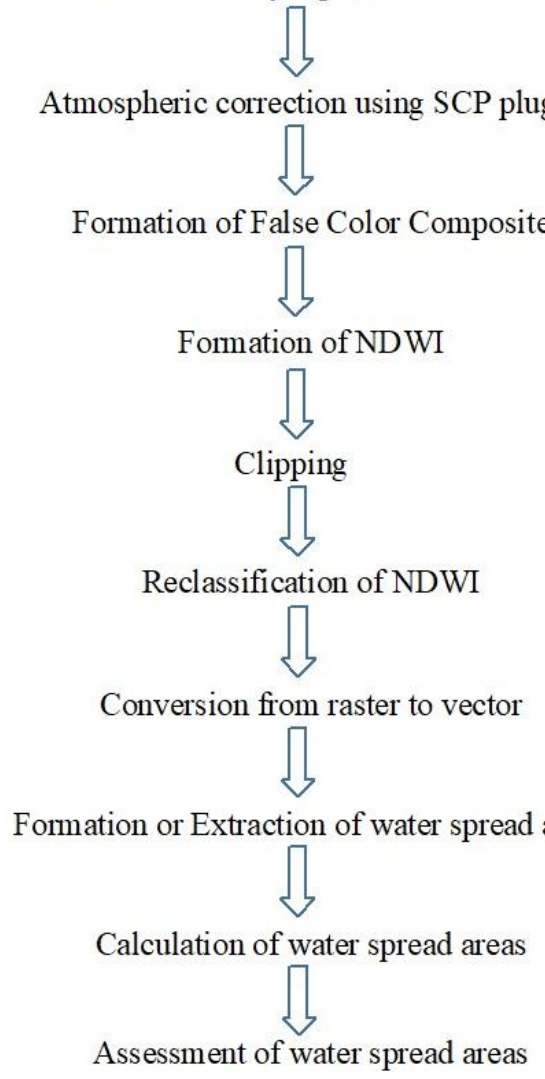

Fig.3 Extracted surface water bodies from 2006 to 2015

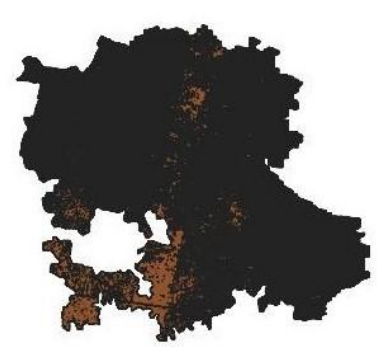

2006

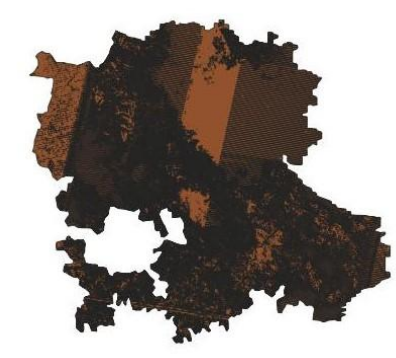

2007 


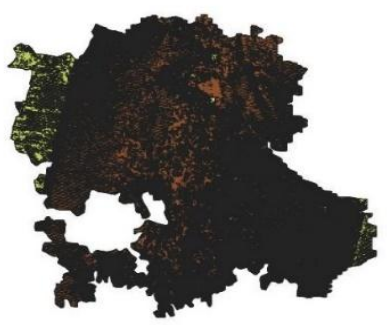

2008

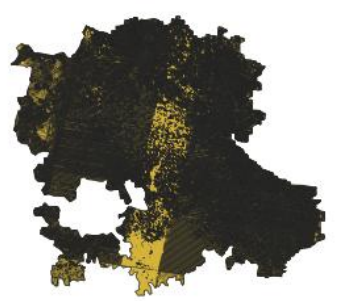

2010

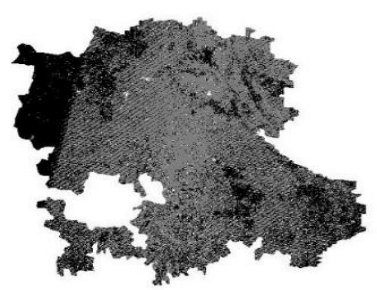

2012

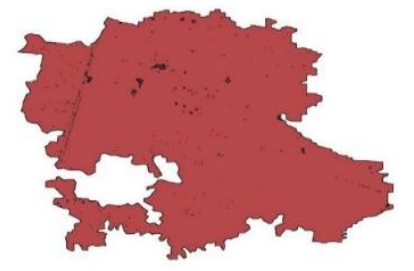

2014

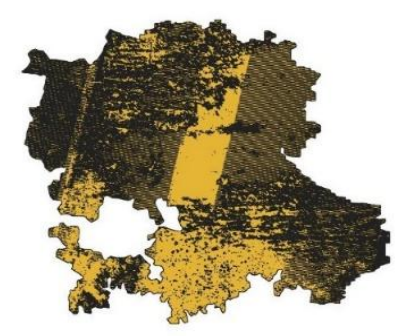

2009

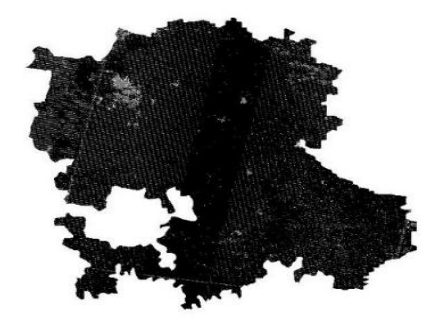

2011

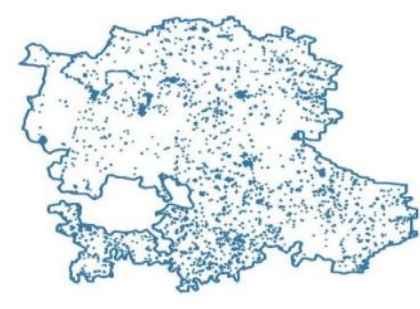

2013

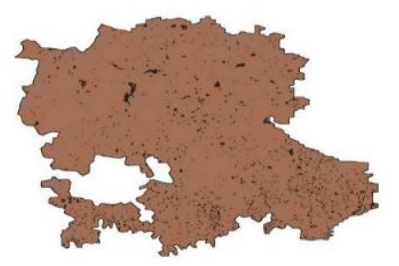

2015

Fig.4 Trend analysis of number of water bodies exist in Anantapur district during 2006-2015

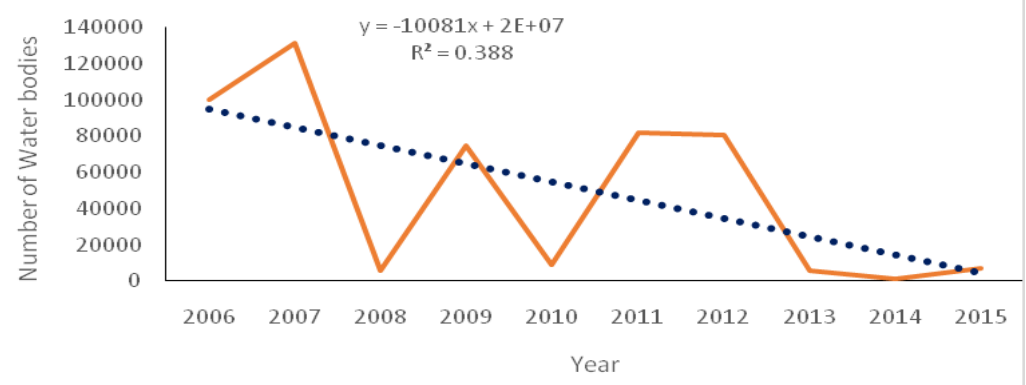


Fig.5 Trend analysis of surface water bodies exist in Anantapur district during 2006-2015

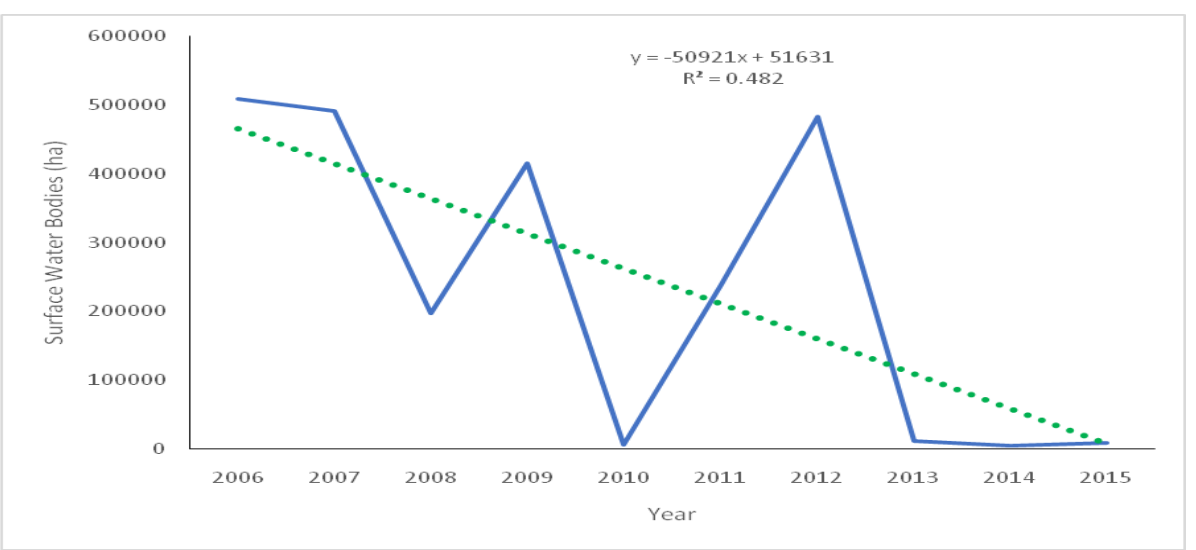

The variation of extracted surface water bodies from 2006 to 2015 as shown in Fig. 3. Trend analysis of number of water bodies as represented in Fig. 4, the regression $\mathrm{R}^{2}$ value is 0.3885 and the maximum and minimum number of water bodies was observed for the year 2014 and 2007 respectively. Trend analysis of surface water bodies as represented in Fig. 5, the $R^{2}$ value is 0.482 and maximum and minimum area of water bodies was observed for the years 2014 and 2006 respectively.

\section{References}

Silviya, K.F., Dobromir, F., and Paulina, R. 2020. Sustainable management of water bodies based on multi-temporal satellite images. $8^{\text {th }}$ International Conference on Cartography and GIS. 1:693-701.

McFeeters, S.K. 1996. The use of the normalized difference water index in the delineation of open water features. International Journal of Remote Sensing. 17(7): 1425-1432.

QGIS.org.2020. QGIS Geographic Information System. Open Source Geospatial Foundation Project. http://qgis.org.

\section{How to cite this article:}

Ashokkumar, N., M.V. Ramana, M. Raghu Babu, P. Prasuna Rani and Ravindra Reddy, B. 2020. Extraction of Surface Water Bodies in Anantapur District Using QGIS. Int.J.Curr.Microbiol.App.Sci. 9(12): 1165-1170. doi: https://doi.org/10.20546/ijcmas.2020.912.141 